\title{
TATA KELOLA PERUSAHAAN YANG MELAKUKAN PENAWARAN UMUM PERDANA SAHAM DISERTAI WARAN (UNIT-IPO FIRMS)
}

\author{
Suherman $^{1 *}$, Gatot Ahmad ${ }^{1}$ \\ ${ }^{1}$ Fakultas Ekonomi, Universitas Negeri Jakarta \\ *suherman@feunj.ac.id
}

\begin{abstract}
:
The purpose of this research is to determine the difference of corporate governance between unit-IPO firms dan share-only IPO firms. Corporate governance is measured with number of directors, number of outsider directors and debt. Sample of this research covers 40 unit-IPO firms listed in Indonesia Stock Exchange between 2007 and 2014. The results show that there is no difference of corporate governance between unit-IPO firms dan share-only IPO firms.
\end{abstract}

Keywords: Corporate governance, unit-IPO firms

\section{PENDAHULUAN}

Penelitian mengenai tata kelola perusahaan (corporate governance) telah banyak dilakukan baik di Indonesia maupun diluar negeri. Isu penelitian corporate governance kebanyakan dikaitkan dengan kinerja perusahaan (Latief, et al., 2014; Guest, 2009; Ghazali, 2010; Peni dan Vahamaa, 2012; Velnampy, 2013). Semakin baik (buruk) mekanisme corporate governance, semakin tinggi (rendah) kinerja perusahaan. Selain dikaitkan dengan kinerja perusahaan, penelitian corporate governance juga dikaitkan dengan kompensasi eksekutif (Suherman, et al., 2010; Suherman, et al., 2015; Yang, et al., 2014; Lee, 2014; Vemala, et al., 2014; Lam, et al., 2013).

Berlainan dengan isu diatas, penelitian ini menginvestigasi mekanisme tata kelola perusahaan dan karakteristik perusahaan yang melakukan penawaran umum perdana saham yang disertai waran atau disebut unit-IPO firms, khususnya mencari tahu apakah unit-IPO firms memiliki mekanisme corporate governance yang kurang efektif dibanding dengan shareonly IPO firms (perusahaan yang melakukan penawaran umum perdana saham tanpa disertai waran) dan menginvestigasi apakah unit-IPO firms memiliki risiko yang lebih tinggi dibandingkan dengan share-only IPO firms. Ketika akan menjual saham ke publik, manajer dihadapkan dua pilihan metode penawaran apakah akan menjual sahamnya ke publik tanpa waran atau dengan disertai waran. Schultz (1993) mengatakan bahwa perusahaan menjual saham disertai waran adalah untuk mengurangi biaya keagenan terkait dengan pendapatan yang diterimanya saat IPO. Howe dan Olsen (2009) berpendapat bahwa waran merupakan suatu mekanisme tata kelola perusahaan bagi perusahaan yang melakukan IPO. Mereka juga mengatakan bahwa waran merupakan sebagai salah satu substitusi pada karakteristik tata kelola perusahaan yang melakukan IPO.

Keputusan metode unit-IPOs ataupun share-only IPOs yang dipilih oleh perusahaan juga tergantung pada konflik keagenan yang ada dalam perusahaan. Schultz (1993) berpendapat bahwa perusahaan yang go public (mengeluarkan saham perdana) yang disertai waran merupakan perusahaan yang menerima dukungan modal ventura. Perusahaan 
tersebut harus merealisasikan tujuan-tujuan yang ditetapkan oleh para pemilik modal ventura tersebut untuk terus berkembang dan menerima dana tambahan. Perusahaan IPO yang mengeluarkan saham disertai waran mendapatkan proceeds dari IPO dalam jumlah yang lebih sedikit dan harus membuktikan kepada pasar bahwa mereka (perusahaan IPO tersebut) mempunyai prospek ekonomi yang baik di masa yang akan datang. Jika pasar bereaksi positif, harga saham perusahaan IPO tersebut naik. Saat harga saham tersebut mencapai harga 'exercise' warannya, para pemegang waran menjual (melakukan exercise) waran tersebut dan memberikan hasilnya (uangnya) ke perusahaan IPO sebagai dana tambahan. Perusahaan yang mengeluarkan waran menerima uang tunai lebih sedikit saat IPO, mengurangi efek arus kas bebas (Jensen, 1986).

Perusahaan IPO yang menjual saham disertai waran (unit-IPOs) memiliki karakteristik ukuran yang lebih kecil, umur lebih muda, dan lebih berisiko dibanding dengan perusahaan IPO yang menerbitkan saham saja (Schultz, 1993; Jain, 1994; How dan Howe, 2001; Howe dan Olsen, 2009). Unit-IPO firms juga melepas sahamnya dalam jumlah yang lebih besar dibanding dengan share-only IPO firms. Schultz (1993) mengemukakan bahwa perusahaan yang lebih muda, lebih kecil dan lebih berisiko memiliki kesulitan yang lebih besar menentukan apakah perusahaan mempunyai proyek-proyek yang menguntungkan untuk dikerjakan. Lebih jauh, jika perusahaan melepas sahamnya dalam jumlah besar saat IPO, biaya keagenan menjadi masalah besar karena para insiders telah mengurangi insentif untuk bertindak atas kepentingan pemegang saham. Perbedaan antara unit-IPO firms dan share-only IPOs menunjukkan bahwa keputusan mengeluarkan waran saat IPO tergantung pada konflik keagenan dalam perusahaan, sama dengan seperti keputusan pembagian dividen yang diutarakan oleh Officer (2006).

Dalam konteks Indonesia, sepengetahuan peneliti, belum pernah dilakukan penelitian mengenai tata kelola perusahaan dan karakteristik perusahaan pada perusahaan yang melakukan IPO baik unit-offerings IPO maupun share-only IPO. Dengan demikian, penelitian ini memperluas literatur terkait corporate governance khususnya di negara berkembang seperti di Indonesia. Secara khusus penelitian ini menguji teori keagenan dalam konteks IPO.

\section{Kerangka Pemikiran Dan Hipotesis}

$\begin{array}{ccc}\text { Howe dan Olsen } & \text { (2009) } \\ \text { mengemukakan } & \text { bahwa jika } & \text { waran }\end{array}$ merupakan substitusi untuk mekanisme tata kelola perusahaan pada perusahaan yang melakukan IPO, perusahaan yang melakukan IPO disertai waran memiliki sruktur tata kelola perusahaan yang kurang efektif dibandingkan dengan perusahaan yang melakukan IPO saham saja (tanpa disertai waran). Sebagai mekanisme tata kelola internal, dewan direktur banyak diteliti. Jensen (1993) dan Yermack (1996) mengungkapkan bahwa semakin besar jumlah dewan direktur, semakin kurang efektif dewan menjalankan fungsinya. Lebih jauh, semakin besar dewan direktur, semakin kurang independen dewan direktur (Weisbach, 1988; Hermalin dan Weisbach, 1998; Howe dan Olsen, 2009).

$\mathrm{H}_{1}$ : Anggota dewan direktur unit-IPO firms lebih banyak daripada anggota dewan direktur shares-only IPO firms yang go public di Bursa Efek Indonesia periode tahun 2011-2014

$\mathrm{H}_{2}$ : Outsiders di dalam dewan direktur unitIPO firms lebih sedikit jumlahnya daripada outsiders didalam dewan direktur shares-only IPO firms yang go public di Bursa Efek Indonesia periode tahun 2011-2014

Perusahaan dengan hutang lebih rendah yang melakukan IPO tidak mendapatkan manfaat dari peran pengawasan yang dilakukan oleh bank dan kreditur lainnya (Diamond, 1984; Fama, 1985; James, 1987; Howe dan Olsen, 2009).

$\mathrm{H}_{3}$ : Hutang unit-IPO firms lebih rendah daripada tingkat hutang shares-only 
IPO firms yang go public di Bursa Efek Indonesia periode tahun 20112014.

\section{METODE Sampel}

Sampel penelitian ini adalah perusahaan yang melakukan IPO disertai waran (disebut unit-IPO firms) periode tahun 2007-2014 di Bursa Efek Indonesia. Jumlah perusahaan yang melakukan IPO disertai waran dari tahun 2007 sampai 2014 berjumlah 40 (empat puluh) perusahaan. Peneliti kemudian membandingkan masingmasing unit-IPO firm dengan masing-masing shares-only IPO firm dalam 1) industri yang sama, dan/atau 2) memiliki total nilai pasar saham yang mendekati (jumlah saham biasa yang beredar setelah IPO dikali dengan harga penawaran).

\section{Variabel Penelitian}

1. Anggota Dewan Direktur

Anggota dewan adalah anggota yang duduk di dewan direktur. Anggota dewan diukur dengan jumlah yang duduk sebagai anggota.

2. Direktur Outsiders

Direktur outsiders adalah dewan direktur yang berasal dari luar perusahaan dan tidak memiliki hubungan keluarga dengan dewan direktur. Direktur outsiders diukur dengan prosentase direktur outsiders terhadap total anggota dewan direktur.

3. Hutang

Hutang adalah kewajiban perusahaan yang harus dilunasi. Hutang diukur dengan debt to equity ratio.

\section{Jenis dan Sumber Data}

Penelitian ini menggunakan data sekunder. Data penelitian diambil dari annual report.

\section{Metode Analisis}

Data dianalisis dengan menggunakan metode uji beda dua kelompok sampel yang berbeda. Dua kelompok pertama ialah unitIPOs dan share-only IPOs.

\section{Uji Hipotesis}

\section{Independent Sample t-test}

Untuk menguji hipotesis penelitian dilakukan uji beda dua kelompok independen (two independent sample t-test). Kelompok pertama ialah tata kelola unit IPO firms, dan kelompok kedua adalah tata kelola shareonly IPO firms.

Untuk menguji hipotesis digunakan rumusan t-test sebagai berikut:

$$
t=\frac{\overline{\mathrm{X}}_{1}-\overline{\mathrm{X}}_{2}}{\sqrt{\frac{S_{x_{1}}^{2}}{n_{1}-1}+\frac{S_{x_{2}}^{2}}{n_{2}-1}}}
$$

dengan degree of freedom $(\mathrm{df})=\left(\mathrm{n}_{1}-1\right)+$ $\left(\mathrm{n}_{2}-1\right)$.

dimana:

$n_{1}$ dan $n_{2} \quad=$ sampel 1 dan 2

$S_{x_{1}}^{2} \operatorname{dan} S_{x_{2}}^{2} \quad=$ varian sampel 1 dan 2

$\overline{\mathrm{X}}_{1} \operatorname{dan} \overline{\mathrm{X}}_{2} \quad=$ Rata-rata nilai sampel 1 dan

2

Setelah t hitung ditentukan, maka $\mathrm{t}$ tabel dicari. Bila t hitung lebih besar (kecil) daripada t tabel, maka perbedaan signifikan (tidak signifikan) terjadi. Tingkat signifikansi adalah 1\%, 5\%, dan 10\%.

\section{HASIL}

\section{Statistik Deskriptif}

Tabel 1. menunjukkan nilai deskriptif baik perusahaan IPO disertai dengan waran (unit-IPOs) di panel A maupun perusahaan IPO tanpa disertai dengan waran (share-only IPOs) di panel B. Rata-rata jumlah direktur yang duduk di perusahaan IPO disertai waran lebih sedikit dibanding dengan di perusahaan IPO tanpa waran (3,68 dibanding 4,28). Sedangkan median jumlah direktur pada perusahaan IPO disertai maupun tanpa waran sama besar yaitu 4. Secara statistik tidak nampak perbedaan yang besar antara jumlah direktur pada perusahaan IPO yang disertai waran dan pada perusahaan IPO tanpa waran. 
Persentase direktur outsider pada perusahaan IPO yang disertai waran dan pada perusahaan IPO tanpa waran menunjukkan angka yang relatif sama. Misalnya, rata-rata persentase direktur outsider perusahaan IPO yang disertai waran sebesar 22,61\%, sementara pada perusahaan IPO tanpa waran sebesar $22,87 \%$. Nilai median perusahaan IPO yang disertai waran dan tanpa waran sama besar, yaitu 4. Lebih jauh, nilai minimum dan maksimum pada perusahaan IPO yang disertai waran dan tanpa waran adalah sama yaitu $0 \%$ dan $50 \%$.

Besarnya hutang (diukur dengan debt to equity ratio) pada perusahaan IPO yang disertai waran dan tanpa waran menunjukkan angka-angka yang tidak jauh berbeda untuk nilai rata-rata dan median. Rata-rata hutang yang dimiliki oleh perusahaan IPO disertai waran sebesar 2,71, sedangkan pada perusahaan IPO tanpa waran adalah 2,89. Sementara itu, nilai median hutang perusahaan IPO yang disertai waran adalah 1,19 dibanding dengan nilai median perusahaan IPO tanpa waran sebesar 1,51. Nilai maksimum hutang pada perusahaan IPO disertai waran dan tanpa waran menunjukkan perbedaan yang cukup jauh, yaitu sebesar 28,82 pada perusahaan IPO yang disertai waran dan sebesar 14,77 pada perusahaan IPO tanpa waran.

Rata-rata umur perusahaan IPO yang disertai waran sedikit lebih muda dibandingkan dengan perusahaan IPO tanpa waran, yaitu 15,95 tahun dan 16,25 tahun. Median umur perusahaan IPO yang disertai waran dan tanpa waran adalah sama besar yaitu 13,50 tahun. Umur minimum pada perusahaan IPO disertai waran dan tanpa waran juga sama yaitu 3 tahun. Sementara umur maksimum perusahaan IPO disertai waran adalah 57 tahun, dan perusahaan IPO tanpa waran sebesar 58 tahun.
Tabel 1. Statistik Deskriptif

\begin{tabular}{|l|c|c|c|c|c|}
\hline & \multicolumn{5}{|c|}{ Panel A: Unit-IPOs } \\
\hline & Min & Mak & Rata-rata & Median & STD \\
\hline Jumlah direktur & 2 & 6 & 3,68 & 4 & 1,02 \\
\hline $\begin{array}{l}\text { Direktur outsider } \\
(\%)\end{array}$ & 0 & 50 & 22,61 & 25 & 15,03 \\
\hline DER & 0,07 & 28,81 & 2,71 & 1,19 & 4,92 \\
\hline $\begin{array}{l}\text { Umur perusahaan } \\
\text { (tahun) }\end{array}$ & 3 & 57 & 15,95 & 13,50 & 11,54 \\
\hline Return awal (\%) & $-81,62$ & 70 & 34,98 & 37,89 & 33,99 \\
\hline $\begin{array}{l}\text { Saham yang dijual } \\
\text { (\%) }\end{array}$ & 10,18 & 70 & 30,74 & 30 & 12,36 \\
\hline $\begin{array}{l}\text { Volatilitas return } \\
\text { (\%) }\end{array}$ & 8,85 & 81,23 & 47,29 & 49,58 & 24,37 \\
\hline $\begin{array}{l}\text { Gross proceeds } \\
\text { (uuta Rp) }\end{array}$ & 22.500 & 2.095 .500 & $338.600,31$ & 220.200 & $431.471,02$ \\
\hline $\begin{array}{l}\text { Waran yang } \\
\text { ditawarkan (juta } \\
\text { lembar) }\end{array}$ & 25,6 & 6.500 & $1.124,83$ & 600 & $1.432,08$ \\
\hline Umur waran & 1 & 5 & 3,22 & 3 & 1,12 \\
\hline Harga exercise (Rp) & 102 & 1.050 & 266,78 & 192,50 & 222,20 \\
\hline \multicolumn{1}{|c|}{ Observasi } & 40 & 40 & 40 & 40 & 40 \\
\hline \multicolumn{7}{|c|}{ Panel B: Share-Only IPOs } \\
\hline & 2 & Mak & Rata-rata & Median & STD \\
\hline Jumlah direktur & 2 & 4,28 & 4 & 1,38 \\
\hline $\begin{array}{l}\text { Direktur outsider } \\
\text { (\%) }\end{array}$ & 0 & 50 & 22,87 & 25 & 11,76 \\
\hline DER & 0,12 & 14,77 & 2,89 & 1,51 & 3,64 \\
\hline $\begin{array}{l}\text { Umur perusahaan } \\
\text { (tahun) }\end{array}$ & 3,00 & 58,00 & 16,25 & 13,50 & 10,07 \\
\hline Return awal (\%) & $-17,27$ & 70,00 & 18,34 & 10,00 & 24,81 \\
\hline $\begin{array}{l}\text { Saham yang dijual } \\
\text { (\%) }\end{array}$ & 10,00 & 73,39 & 26,32 & 25,00 & 14,21 \\
\hline $\begin{array}{l}\text { Volatilitas return } \\
\text { (\%) }\end{array}$ & 2,21 & 80,22 & 28,65 & 17,25 & 26,89 \\
\hline $\begin{array}{l}\text { Gross proceeds } \\
\text { (juta Rp) }\end{array}$ & 30.100 & 2.064 .873$, & $337.411,34$ & $217.114,01$ & $421.332,36$ \\
\hline \multicolumn{1}{|c|}{ Observasi } & 40 & 40 & 40 & 40 & 40 \\
\hline
\end{tabular}

Sumber : data diolah

Rata-rata return awal menunjukkan selisih yang cukup besar dimana perusahaan IPO disertai waran memiliki rata-rata return awal-nya sebesar $34,98 \%$ dan perusahaan IPO tanpa waran adalah 18,34\%. Median return awal perusahaan IPO yang disertai waran dan tanpa waran adalah 37,89\% dan $10 \%$. Return awal minimum pada perusahaan IPO disertai waran dan tanpa waran adalah $-81,62 \%$ dan 17,27\%. Sementara return awal maksimum perusahaan IPO yang disertai waran dan tanpa waran adalah sama, yaitu 70\%.

Rata-rata saham yang dilepas ke publik pada perusahaan IPO disertai waran lebih tinggi daripada perusahaan IPO tanpa waran, yaitu 30,74\% berbanding 26,32\%. Nilai median-nya pun lebih besar pada perusahaan IPO disertai waran dibanding dengan perusahaan IPO tanpa waran, yaitu $30 \%$ versus $25 \%$. Namun nilai maksimum saham yang dijual ke publik oleh perusahaan IPO yang disertai waran lebih kecil (sebesar $70 \%$ ) dibanding dengan perusahaan IPO tanpa waran (sebesar 73,39\%). Sementara nilai minimum saham yang dijual ke publik oleh perusahaan IPO yang disertai waran lebih besar (yaitu 10,18\%) dibanding dengan 
perusahaan IPO tanpa waran (yaitu sebesar $10 \%)$.

Rata-rata volatilitas return perusahaan IPO yang disertai waran lebih tinggi dibandingkan dengan perusahaan IPO tanpa waran, yaitu 47,29\% melawan $28,65 \%$. Nilai terendah dan tertinggi volatilitas return perusahaan IPO yang disertai waran adalah 8,85\% dan 81,23\%. Sementara nilai terendah dan tertinggi volatilitas return perusahaan IPO tanpa waran adalah 2,21\% dan 80,22\%. Nilai standar deviasi volatilitas return perusahaan IPO yang disertai waran lebih rendah (yaitu 24,37\%) dibandingkan dengan perusahaan IPO tanpa waran (26,89\%).

Rata-rata penerimaan kotor dari penjualan IPO (gross proceeds) perusahaan IPO yang disertai waran lebih besar dibandingkan dengan perusahaan IPO tanpa waran, yaitu 338,6 milyar rupiah berbanding 337,4 milyar rupiah. Gross proceeds minimal dan maksimal perusahaan IPO yang disertai waran adalah 22,5 milyar rupiah dan 2,09 trilyun rupiah. Sementara gross proceeds perusahaan IPO tanpa waran adalah 30,1 milyar rupiah dan 2,06 trilyun rupiah.

Tabel 1 panel A (unit-IPOs) menunjukkan jumlah waran yang dijual, umur waran dan harga exercise. Rata-rata waran yang dijual adalah sebesar 1,12 milyar lebih lembar. Median waran yang ditawarkan adalah sebanyak 600 juta lembar. Waran terendah dan terbanyak yang ditawarkan adalah sebesar 25,6 juta lembar dan 6,5 milyar lembar. Sementara standar deviasinya tinggi yaitu sebesar 1,43 milyar lebih lembar. Umur waran memiliki usia rata-rata selama 3,22 tahun. Mediannya 3 tahun. Usia waran tercepat dan terlama adalah 1 tahun dan 5 tahun. Rata-rata harga exercise adalah Rp.266,78 dengan standar deviasinya Rp. 222,20. Median harga exercise sebesar Rp. 192,50. Harga exercise terendah dan tertinggi adalah Rp.102 dan Rp.1.050.

\section{PEMBAHASAN}

Tabel 2 menunjukkan hasil uji beda perusahaan IPO disertai waran (unit-IPO firms) dan perusahaan IPO tanpa waran (share-only IPO firms). Uji beda menggunakan uji t dan uji Z (Wilcoxon test). Corporate governance menggunakan tiga proksi yaitu jumlah direktur, direktur outsider dan debt to equity ratio. Jumlah direktur di perusahaan IPO yang disertai waran berbeda signifikan dengan jumlah direktur di perusahaan IPO tanpa waran dimana rata-rata jumlah direktur di perusahaan IPO dengan waran lebih banyak dibanding di perusahaan IPO tanpa waran. Hal tersebut dilihat dari nilai t sebesar 2,212 (signifikan pada 95\%) dan nilai $\mathrm{Z}=2,029$ (signifikan pada 95\%). Hasil ini bertentangan dengan Howe dan Olsen (2009) yang menemukan jumlah direktur pada perusahaan IPO yang disertai waran lebih banyak dibanding dengan di perusahaan IPO tanpa waran. Yawson (2006) mengemukakan bahwa ukuran dewan yang besar menimbulkan tingginya biaya manejerial yang menyebabkan turunnya profitabilitas. Jumlah anggota dewan direktur yang banyak bisa menimbulkan masalah komunikasi dan koordinator yang mana dapat secara negatif mempengaruhi kinerja perusahaan (Yermack, 1996).

Tabel 2. Hasil Uji Beda

\begin{tabular}{|c|c|c|c|c|c|c|}
\hline & \multicolumn{2}{|c|}{ Unit-IPO firms } & \multicolumn{2}{|c|}{$\begin{array}{l}\text { Shares-only IPO } \\
\text { firms }\end{array}$} & \multicolumn{2}{|c|}{ Difference test } \\
\hline & Mean & Median & Mean & Median & $t$ & $\mathbf{Z}$ \\
\hline Jumlah direktur (orang) & 3,68 & 4,00 & 4,28 & 4,00 & $2,212^{\mathrm{b}}$ & $2,029^{b}$ \\
\hline Direktur outsider (\%) & 22,61 & 25,00 & 22,87 & 25,00 & 0,090 & 0,700 \\
\hline Debt to equity ratio & 2,71 & 1,19 & 2,89 & 1,51 & 0,239 & 0,245 \\
\hline
\end{tabular}

Dua proksi lain corporate governance yaitu direktur outsider dan debt to equity ratio tidak menunjukkan perbedaan yang signifikan pada perusahaan IPO yang disertai waran maupun pada perusahaan IPO yang tanpa waran. Nilai uji $\mathrm{t}$ dan $\mathrm{z}$ pada direktur outsider hanya 0,090 dan 0,700. Sedangkan nilai $\mathrm{t}$ dan $\mathrm{z}$ debt to equity ratio sebesar 0,239 dan 0,245. Hasil tersebut tidak mendukung temuan Howe dan Olsen (2009) yang mengungkapkan ada perbedaan signifikan jumlah direktur outsider dan debt to equity ratio antara perusahaan IPO yang disertai waran dan perusahaan IPO tanpa waran. Secara umum dapat dikatakan bahwa mekanisme corporate governance pada 
perusahaan IPO yang disertai waran dan pada perusahaan IPO tanpa waran adalah tidak berbeda.

\section{Kesimpulan dan Saran}

Ketika perusahaan memutuskan akan "go public", manajemen perusahaan dihadapkan pada dua pilihan yaitu 1) menjual saham perdananya disertai waran (disebut unit-IPOs), atau 2) menjual saham saja tanpa disertai waran (disebut share-only IPOs). Unit-IPOs memberikan hak bagi pemiliknya untuk membeli saham pada harga yang telah disepakati di awal dalam jangka waktu tertentu. Dari sudut pandang praktis, penjualan saham perdana disertai waran dinamakan sebagai "sweeteners". Tujuan penelitian ini adalah menguji tata kelola perusahaan antara unit-IPO firms dan shareonly IPO firms. Hasil penelitian menunjukkan bahwa tidak ada perbedaan tata kelola perusahaan antara unit-IPO firms dan share-only IPO firms.

Penelitian ini hanya menggunakan tiga pengukuran tata kelola perusahaan. Untuk penelitian selanjutnya disarankan untuk menggunakan lebih banyak pengukuran tata kelola perusahaan dan lebih banyak sampel.

\section{DAFTAR PUSTAKA}

$\begin{array}{lrl}\text { Diamond, D., } 1984 . & \text { "Financial } \\ \text { Intermediation } & \text { And } & \text { Delegated } \\ \text { Monitoring". Review of } & \text { Economic } \\ \text { Studies 51, Pp.393-414. } & \end{array}$

Fama, E., 1985. "What's Different About Banks?” Journal Of Monetary Economics 15, Pp.29-39.

Ghazali, N. A. M. 2010. "Ownership Structure, Corporate Governance, And Corporate Performance In Malaysia”. International Journal of Commerce And Management, 20, 2, Pp.109-119.

Guest, P. M. 2009. “The Impact Of Board Size On Firm Performance: Evidence From UK”. European Journal of Finance, 15, 4, Pp.385-404.
Hermalin, B., dan Weisbach, M., 1998. "Endogenously Chosen Boards Of Directors And Their Monitoring Of The CEO”. American Economic Review 88, Pp.96-118.

How, J., dan Howe, J., 2001. "Warrants In Initial Public Offerings: Empirical Evidence”. Journal of Business 74, Pp.433-457.

Howe, J. dan Olsen, B. 2009. "Security Choice And Corporate Governance”. European Financial Management, 15, 4, Pp.814-843

Jain, B.A., 1994. "Unit IPOs: A Mechanism For Small Businesses To Go Public". Journal of Small Business Management 32, 57-68.

James, C., 1987. "Some Evidence On The Uniqueness Of Bank Loans”. Journal Of Financial Economics 15, Pp.29-39.

Jensen, M., 1986. “Agency Costs Of Free Cash Flow, Corporate Finance, And Takeovers". American Economic Review 76, Pp.323-329.

Jensen, M., 1993. "The Modern Industrial Revolution, Exit, And The Failure of Internal Control Systems”. Journal of Finance 48, Pp.831-880.

Lam, K.C.K. Mcguiness, P B., dan Vieito, J. P. 2013. "CEO Gender, Executive Compensation And Firm Performance In Chinese-Listed Entreprises”. Pacific-Basin Finance Journal, 21, Pp.1136-1159.

Latief, R., Raza, S. H., dan Gillani, S. A. H. 2014. "Impact Of Corporate Governance On Performance Of Privatized Firms: Evidence From NonFinancial Sector Of Pakistan”. MiddleEast Journal Of Scientific Research, 19, 3, Pp.360-366. 
Lee, K. W. 2014. “Compensation Committee And Executive Compensation In Asia”. International Journal of Business, 19, 3, Pp.213-236.

Officer, M.S., 2006. "Dividend Policy, Dividend Initiations, And Governance". Unpublished Working Paper. University of Southern California.

Peni, E. dan Vahamaa, S. 2012. "Did Good Corporate Governance Improve Bank Performance During The Financial Crisis?”. Journal Of Financial Services Research, 41, 1, Pp.19-35

Schultz, P., 1993. "Unit Initial Public Offerings: A Form Of Staged Financing”. Journal of Financial Economics 34, Pp.199-229.

Suherman, Wulan Rahmawati, dan Agung D. Buchdadi. 2010. "Firm Performance, Corporate Governance, And Executive Compensation In Financial Firms Evidence In Indonesia". Working Paper, www.ssrn.com

Suherman, Fitriawan, R., dan Ahmad, G. N. 2015. "Pengaruh Kinerja Perusahaan, Kepemilikan Institusi, Dan Komisaris Independen Terhadap Total Kompensasi: Studi Pada Perusahaan Yang Terdaftar Di LQ45 Tahun 20092012”. Jurnal Aplikasi Manajemen, Pp.516-526.

Velnampy, T. 2013. “Corporate Governance And Firm Performance: A Study Of Sri Lankan Listed Manufacturing Companies”. Journal of Economics And Sustainable Development, 4, 3, Pp.228-236.

Weisbach, M., 1988. "Outside Directors And CEO Turnover”. Journal Of Financial Economics 20, Pp.431-460.
Yang, F., Dolar, B., dan Mo, Lun. 2014. "CEO Compensation And Firm Performance: Did The 2007-2008 Financial Crisis Matter?” Journal of Accounting And Finance, 14, 1, Pp.137-146.

Yawson, A. "Evaluating The Characteristics Of Corporate Boards Associated With Layoff Decisions”, Corporate Governance: An International Review, vol.14, no.2, Pp.75-84

Yermack, D., 1996. "Higher Market Valuation Of Companies With A Small Board Of Directors". Journal of Financial Economics 40, Pp.185-211

Vemala, P., Nguyen L., Nguyen, D, dan Kommasani, A. 2014. "CEO Compensation: Does Financial Crisis Matter?” International Business Research, 7, 4, Pp.125-131. 